IJ§ER

ISSN: 2149-5939
International Journal of Social Sciences and Education Research

Online, https://dergipark.org.tr/tr/pub/ijsser

Volume: 7(2), 2021

\title{
Attractiveness of the city, psychological and social capital: Never-ending migra- tion from rural settlements to urban centers in Turkey
}

\author{
Şerafettin Keleş ${ }^{\mathrm{a}}$ \\ ${ }^{a}$ Assist Prof., Department of Economics, Faculty of Economics and Administrative Sciences, Erzincan University, Erzincan, Turkey, ORCID: \\ https://orcid.org/0000-0002-5147-0825 skeles2580@gmail.com

\begin{tabular}{|c|c|}
\hline Article Info & Abstract \\
\hline Research Article & \multirow{9}{*}{$\begin{array}{l}\text { There is a continuous act of inward migration from rural settlements to urban centers. The } \\
\text { attractiveness of the city and the repulsion of the countryside are cited as the reasons for } \\
\text { internal migration. This study empirically investigates the attractiveness of the city, which } \\
\text { encourages rural migration, and the effect of psychological and social capital on the attrac- } \\
\text { tiveness of the city. The cross-sectional data of the study was formed by the face-to-face } \\
\text { survey of } 280 \text { individuals who live in the rural area of Erzincan and want to migrate to city } \\
\text { centers. In the analyzes made with the Structural Equation Modeling, it has been determined } \\
\text { that there is a linear relationship between the attractiveness of the city, which encourages } \\
\text { rural migration, and positive psychological capital, bonding social capital and bridging so- } \\
\text { cial capital. }\end{array}$} \\
\hline Received:25 December 2020 & \\
\hline Revised: 16 March 2021 & \\
\hline Accepted: 22 March 2021 & \\
\hline Keywords: & \\
\hline Immigration, & \\
\hline Attractiveness of the city, & \\
\hline Positive psychological capital, & \\
\hline $\begin{array}{l}\text { Bonding social capital, } \\
\text { Bridging social }\end{array}$ & \\
\hline
\end{tabular}

\section{Introduction}

Migration, which has a history as old as human history, is based on social, political, economic and many different reasons. Individuals had to leave the geography where they were born and grew up, sometimes voluntarily and sometimes involuntarily due to the force of the circumstances. While natural disasters such as drought, flood, earthquake and fire that occurred against the will of individuals constituted the most important reasons of migration throughout history, economic, social and political events after the industrial revolution, where cities gained importance, constituted the reasons for migration (Keleş R., 1996). Again, in parallel with the recent developments in technology, transportation and communication, people's willingness to lead a better life has greatly increased migration (Sencer, 1979).

Migration mobility in which individuals are relocated within the borders of the country is defined as internal migration (Lewis, 1982). The intensification of recruitment in Turkey began with the industrialization and urbanization process in the late 1950s. Turkish society, which is an agricultural society, has entered into a process of rapid industrialization and urbanization, and thus education, health, culture, infrastructure services and economic conditions in urban areas have become more convenient and attractive than rural areas. This situation made rural areas "unattractive", urban areas "attractive" and caused a significant concentration of rural population to urban areas (Sağlam, 2006; Kıray, 2007). Internal migration of individuals from rural to urban areas; The spread of agricultural mechanization and the opening of agriculture to technology, factors such as low factor productivity due to intensive agricultural practices, redistribution of land by inheritance and insufficient land for production, rapid growth of the rural population and low living standards in the countryside are promoting the "push/unattractive" factors of the countryside. The desire to benefit from the rapidly developing social and cultural opportunities in the cities, the concentration of health facilities in the city centers, the fact that cities are more attractive for business, the developments in communication and transportation facilities, the abundance of educational opportunities and options have made "attractive" cities (Gür \& Emel, 2004; Gürbüz \& Karabulut, 2008; Dücan, 2016).

* Data of this research was gathered in 2018. No potential conflict of interest was reported by the authors. All responsibility belongs to the researcher. All parties were involved in the research of their own free will.

To cite this article: Keleş, Ş. (2021). Attractiveness of the city, psychological and social capital: Never-ending migration from rural settlements to urban centers in Turkey. International Journal of Social Sciences and Education Research, 7 (2), 151-161. DOI: https://doi.org/10.24289/ijsser.846777

Copyright (C) 2021 by IJSSER

ISSN: 2149-5939 
The informal social networks developed by immigrants to cope with the problems of finding employment and settlement after migration, make the migration from rural areas to city centers continuous (Çağlayan, 2006). Social capital, which expresses the relationships individuals establish with other individuals, turns into a very beneficial and productive activity for the individual when used to achieve his/her goals (Coleman, 1988). Social capital is defined as the sum of the resources that accrue to an individual or a community by having a network of relationships based on friendship, trust and loyalty, which is the result of mutual recognition of individuals and long-term relationships (Bourdieu \& Wacquant, 1992). Social capital functions as contact points of information and opportunity source for individuals (Burt, 1999; Fukuyama, 2002). The social networks formed by the social capital between the countryside and the city always remind the city's blessings (attractiveness) and perpetuate migration.

Positive psychology, which encourages individuals to migrate, focuses on the opportunities provided by modern life to individuals and the achievement of a happy life instead of individuals' failure, desperation and burnout (Caprara \& Cervone, 2003). Positive psychology can be defined as examining the processes and conditions that contribute to the development of individuals (Gable \& Haidt, 2009). In other words, positive psychology focuses on how individuals' self-confidence and hopes can be developed (Luthans, Vogelgesang \& Lester, 2006). The attractiveness of the city in rural migration encourages rural migration by creating self-confidence and hope on the individual.

While social, political, economic and cultural processes have a great place in the studies on migration in the literature, the intangible capital and psychological processes of individuals have been neglected. This study reveals the effects of individuals' psychological states and their individual intangible capital on migration motivation with a holistic model. The study based on sociology of economics measures the psycho-social processes of individuals related to internal migration with the survey method and makes a significant contribution to the literature in this context.

\section{Theoretical framework}

\subsection{The attractiveness of the city and the repulsion of the countryside}

Widespread employment and education opportunities in cities is the primary reason for rural-urban migration (Başel, 2007). Another reason is the income inequality between the rural areas and the cities and the high level of hidden unemployment in the countryside. Again, while the population growth rate is high in rural areas, the economic development rate is very low. The rapid development of urban infrastructure and the neglect of rural infrastructure, with the work of local governments and the support of central policies, have caused the gap in infrastructure and services between the city and the countryside. Infrastructure, health facilities, education and cultural services are attractive to the city; made the countryside unattractive (Gökçe, 1996). Although internal migration is generally attributed to the attractiveness of the city and the repulsion (unattractiveness) of the countryside, each country has economic, social, political and reasons depending on its specific conditions (Kartal, 1978).

Despite the effect of cities being attraction centers, migration distance is an important factor. Migration distance and post-migration opportunities are considered by individuals (Stouffer, 1940). Again, in individuals' decision to migrate, positive and negative factors likely to be encountered during the migration process are also taken into account (Lee, 1969).

\subsection{Positive psychological capital}

Positive psychology aims to reveal and develop the strengths and positive aspects of individuals and to this end, it investigates how individuals can be happier, more successful and better (Linley et al., 2006). In other words, positive psychology does not care about what is wrong with individuals; It deals with what is right in the individual and how this truth can be developed. Because, individuals consider positive events to be "permanent and correct". Adverse events are temporary (Avey et al., 2009).

Individual's positive perception of life and joy of life constitute his positive psychological capital. Positive psychological capital emphasizes the positive characteristics for the individual to survive even in adverse conditions (Luthans, Vogelgesang \& Lester, 2006). Individual positive psychological capital;

- Self-confidence and self-efficacy that the individual can show the necessary strength and effort to accomplish difficult tasks,

- Positive expectation and optimism about always being successful even under difficult conditions,

- The desire and hope of the individual to reach his goal, 
- Whether the individual is able to survive and resist in the face of difficulties and adversity, It is expressed with its characteristics and is defined as a positive psychological structure that contributes to the development of the individual.

\subsection{Bonding social capital}

Bonding Social Capital consists of equal and horizontal relationships established between individuals in a community. These relationships between individuals and groups who have ethnic, socioeconomic and cultural homogeneity and share the same value judgments can be established within the scope of kinship, neighborhood or family (Narayan \& Pritchett, 1999). In order for an established bond to be considered as bonding social capital, individuals in communication must be from the same community. Bonding social capital is the social capital that contains the highest level of trust compared to other types of social capital (Adler \& Kwon, 2002). Representing relationships between family or members of the same ethnic group, village and neighborhood, the bonding social capital approach emerges from the intrinsic bonds between the individuals that make up a community and becomes a "public good" that individuals in that community benefit from in achieving common goals (Özen \& Aslan, 2006). In this framework, in the bonding approach, social capital becomes a "cultural" feature that is at the core of the social structure and internalized by individuals through socialization processes (Harrison \& Huntington, 2000).

The source of binding social capital is the system of values and beliefs that regulate social relations within the community in which we live. Trust in other individuals living in the community forms the basis of relationships. In general, trust is defined as an individual being confident in the behavior of other individuals and feeling at peace. The individual trusts the other because they are part of the relative, village and family (Keskin \& Keleş, 2018). Because of trust in the bonding social capital approach, individuals have the belief that they will not exploit their vulnerability as they assume that other individuals will comply with moral norms (Korczynski, 2000).

\subsection{Bridging social capital}

Bridging Social Capital derives from weaker and less intense but more diverse social ties, such as business friendship, acquaintance or friendships through social networks, outside the individual's family, village, relatives, and ethnic group in which the individual lives and it connects to more distant acquaintances (Özen \& Aslan, 2006).

Bridging social capital refers to relationships between individuals who share many similar demographic characteristics but are not very close to each other. This type, which points to the ties that extend beyond the community in which the individual lives, ensures that ideas, knowledge and resources are obtained from official institutions (Woolcock, 2002). Because of the dominant values of the Turkish people such as collectivism, uncertainty avoidance and power distance, an environment cannot be created that will enable the foreigner to trust the foreigner, and individuals only rely on the people they are connected to with primary ties such as kinship and fellowship (Sargut, 2003). As a result, it is argued that a fragmented social structure has emerged, consisting of cliques or communities that are self-contained and not in solidarity with other groups in order to achieve social goals (Özen \& Aslan, 2006).

\section{Methodology}

Data of this research was gathered in 2018. No potential conflict of interest was reported by the authors. All responsibility belongs to the researcher. All parties were involved in the research of their own free will.

\subsection{Material}

In the study, a Structural Equation Model was created based on the attractiveness of cities, positive psychological capital and social capital issues literature. In the Structural Equation Model, the cross-sectional data obtained from the surveys conducted in 2018 with individuals living in rural settlements and engaged in agriculture in Erzincan central district were used as study material. The data were obtained by random sampling method. The surveys were conducted with volunteers. The analysis of the model was carried out with LISREL 8.72 and SPSS 21 package programs.

\subsection{Method}

\subsubsection{Determining sample size}

The total population in rural settlements of Erzincan central district is 18730 people (Anonymous, 2019b). The Random Sampling Method was preferred and the number of questionnaires was calculated using Yamane's (1967) formula. 


$$
n=\frac{\mathrm{N} \cdot \mathrm{P} \cdot \mathrm{Q} \cdot \mathrm{Z}^{2}}{(\mathrm{~N}-1) \cdot \mathrm{d}^{2}+\mathrm{P} \cdot \mathrm{Q} \cdot \mathrm{Z}^{2}}
$$

In the formula, $\mathrm{n}=$ sample size, $\mathrm{N}=$ population of the settlement, $\mathrm{P}=$ those who want to migrate, $\mathrm{Q}=$ those who do not want to migrate, $Z=\%(1-\alpha) Z$ test value, $\alpha=$ significance level, $d=$ error (tolerance) share. $Z$ Confidence coefficient $95 \%$ confidence coefficient was taken as 1.96 . The rate of those who want to migrate to work with a large sample was taken as 0.5 and the sample size was calculated as 280 .

\subsubsection{Preparation of survey questions and analysis process}

The questionnaire questions were originally created based on the city's attraction, positive psychological capital, bonding social capital and bridging social capital studies in the literature. The scale questions prepared for the research were measured with Likert method with 1, I do not agree, 2, I slightly agree 3, I agree 4, and I strongly agree with 5 points. The study was carried out with Structural Equation Modeling analyzes.

\subsubsection{Structural equation modelling}

Structural equation models are frequently used in many different disciplines (Bentler \& Yuan, 1999; Raykov \& Marcoulides, 2006) to measure a specific theoretical relationship (Jöreskog \& Sörbom, 1993), and to test the relationships between observed and latent variables (Hoyle, 1995; Leech et al., 2005; İlhan \& Çetin, 2014). The fact that structural equation models take into account the measurement errors and deficiencies of observed variables different from traditional econometric measurement methods (Hershberger, 2003), they are used extensively in many different areas. Another reason is that it can show direct and indirect effects between variables and allows multivariate model development, prediction and testing (Lomax \& Schumacker, 2004; Pituch \& Stevens, 2009).

Structural equation models (SEM) allow analysis with a large number of variables. It is possible to use many observed and latent variables together in the model. Structural Equation Modeling is highly preferred in social sciences because it allows researchers to build large multivariate models (Fornel, 1987; Blanthorne et al., 2006; Nitzl, 2016). This study adopted the structural equation model to test many variables that accelerate rural migration together.

The structure and relationships that cause recruitment from rural areas to urban areas constitute the subject of this study. The theoretical model of the study is shown in Figure 1 below.

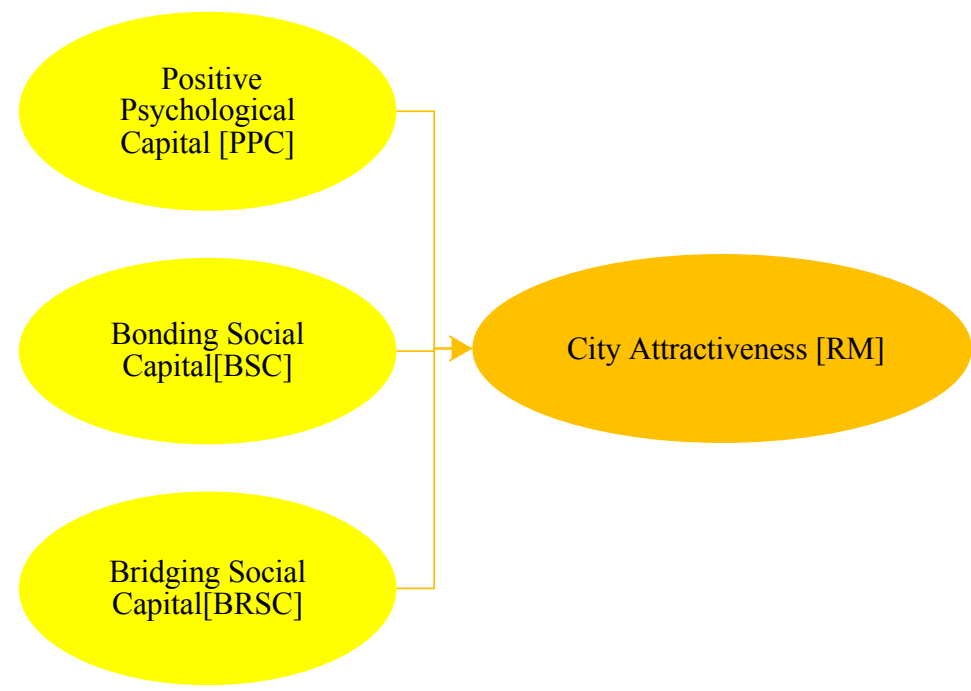

Figure 1. Individual abstract capitals that affect the attractiveness of the city

\subsection{Latent variables of the working model}

\subsubsection{City attractiveness (RM)}

Individuals living in rural areas feel a desire to migrate to big cities due to the "attractive" features of city life. The reason for individuals' migration from rural to urban is to provide a better standard of living for their families. In rural migration, places with developed industrial and service sectors, strong social and physical infrastructure and need for labor are preferred (Balcioğlu, 2011). Scale questions are in five-point likert structure. Survey questions and icons are below. 
CRM1- Living in the city is easier.

CRM4- Health services and social facilities are better in the city

CRM6- The economic and social contribution of the city to me and my family will be higher.

CRM8- I want to benefit from the city's education, infrastructure and transportation services

CRM9- I believe I will make more money in the city

CRM10- Living conditions in the city are good.

\subsubsection{Positive psychological capital (PPC)}

Positive psychology aims to reveal and develop the strengths and positive aspects of individuals and searches how individuals can be happier, more successful and better for this. Individuals' expectations from cities, selfconfidence and self-efficacy, hope and joy of life constitute their positive psychological capital. The questions in the scale are five-point likert.

PS1- Leaving my village will not be difficult for me

PS2- In my opinion, there is a life in the city close to my ideals.

PS3- I will be pleased with my life in the city.

PS4- My life in the city will change positively over time

\subsubsection{Bonding social capital (BSC)}

The effect of social capital on migration has been studied in different studies. It has shown that family ties have a different effect on migration decision within the context of bonding social capital (Spilimbergo \& Ubeda, 2004). Individuals can access social capital through membership in social networks and social institutions, and transform their social capital into forms of capital to improve their position in society (Coleman, 1988; Bourdieu, 1989). Social networks are a set of interpersonal networks that connect them through kinship, friendship, and fellow countrymen relationships. Network connections increase the possibility of migration. The social capital scale questions below are in five-point likert structure.

B1- I have a strong bond with my relatives in the city.

B2- I care about my relatives in the city.

B4- I often meet with relatives and friends in the city.

B6- I trust my relatives and friends.

\subsubsection{Bridging social capital (BRSC)}

Social networks established through bridging social capital decrease the movement costs and risks of individuals and the expected net returns for migration are increasing. The ties established by immigrants offer an important transfer of financial capital, that is, savings in the country and sending money home (Palloni et al., 2001). The social capital scale questions below are in five-point likert structure.

BR1- People are generally reliable.

BR2- I can communicate with any person.

BR4- Gives confidence the justice system to me

BR5 I- deal with issues that occupy the country agenda.

\section{Findings}

\subsection{Demographic and socioeconomic findings}

The demographic and sociocultural characteristics of the individuals who participated in the face-to-face survey study in the rural area of Erzincan province are given below. Under the assumption that there will be a relationship between the ages of individuals and migration and social capital, importance has been given to surveying individuals from all age groups. The age, education and income groups and percentage distribution of the individuals surveyed are given in Table 1 below. 
Table 1. Demographic Characteristics of the Participants

\begin{tabular}{lcc}
\hline Age & n (frequency) & $\%$ \\
\hline $25-29$ & 31 & 11,1 \\
$30-35$ & 59 & 21,1 \\
$36-45$ & 66 & 23,6 \\
$46-60$ & 66 & 23,6 \\
$61+$ & 58 & 20,07 \\
\hline Education & & 26,8 \\
\hline Primary school & 75 & 28,9 \\
Middle School & 81 & 25 \\
High school & 70 & 2,5 \\
Undergraduate & 7 & 16,8 \\
License & 47 & 2,1 \\
\hline Monthly Income (TRY) & & 17,9 \\
\hline $700-1200$ & 2 & 60,4 \\
$1300-1700$ & 50 & 16,1 \\
$1800-2200$ & 169 & 3,6 \\
$2300-2700$ & 45 & 10 \\
\hline
\end{tabular}

Source: Original calculation

Considering the existence of a relationship between the education status of individuals and migration in rural migration studies, attention has been paid to have participants from every education group. $26.8 \%$ of the participants are primary school, $28.9 \%$ secondary school, $25.0 \%$ high school, $2.5 \%$ associate degree $16.8 \%$ graduate. It is known that the income level of families is an important factor in the rural migration decision. The monthly total family income levels of the participant individuals were determined as $2.1 \%$ between $700-1200 \mathrm{TRY}, 17.9 \%$ between 1300 - 1700 TRY, 60.4\% between 1800 - 2200 TRY, 16.1\% between $2300-2700$ TRY and 3.6\% over 2700 TRY.

\subsection{Structural equation modeling findings}

The data obtained from the survey study was analyzed with SPSS 21 statistical package program and Lisrel 8.72 package program. Averages, st \& back deviations and reliability tests of the data were made with the SPSS 21 package program. Cronbach's Alpha coefficient was calculated as the most widely used method for reliability tests. Later, Structural Equation Modeling analysis was performed with Lisrel 8.72 package program, standardized factor load values and t values of observed variables were calculated. The calculations of the observed variables are below, in Table 2 .

One of the observed variables of the Unifying Social Capital Latent Variable in the model, "BR1 People are generally reliable." Since the $t$ value of the variable is less than \pm 1.96 , it was not found statistically significant at $5 \%$ significance level. The $t$ values of other observed variables in the model were found to be statistically significant at the $5 \%$ significance level, since the $t$ values were greater than \pm 1.96 . Chi-square / degree of freedom (ChiSquare / df), p value and RMSEA (Root-mean-square error approximation) values were examined as measurement criteria used to evaluate the fit between data and model. The value of $X^{2} / \mathrm{df}$ (404.92/ 113) for the model was calculated as 3.57. This value is within the acceptable values of five and less than five. Likewise, the RMSEA value is still within acceptable limits (0.096). Since the model takes the value of $p<0.0000$, it is statistically significant at 5\% significance level.

The structural model shows explanatory relationships between latent variables (Raykov \& Marcoulides, 2006). In other words, the structural model is a model used to test the relationships between latent variables (Weston \& Gore, 2006). Structural equation modeling includes observed and latent variables together, and latent variables are defined by observed variables (Kahn, 2006; Tabachnick \& Fidell, 2007). Including dependent and independent variables constitutes the direction of canonical correlation and definition of causal relationships between variables constitutes the aspect of regression analysis (Tabachnick \& Fidell, 2007). Standardized values (regression values) are given in the structural equation model shown in Figure 2 below.

In Figure 3, $t$ values of the city's attractiveness structural model are given. Accordingly, Positive Psychological Capital $(t=13.61)$ and Bonding Social Capital $(t=8.55)$ were found statistically significant at $5 \%$ significance level, respectively. However, since Bridging Social Capital has a $t$ value $(t=1.45)$, it was not found statistically significant at 5\% significance level. 
Table 2. Calculations for observed variables

\begin{tabular}{|c|c|c|c|c|c|}
\hline Observed variables & Means & Standard deviation & $t$ values & Factor load values & $\begin{array}{c}\text { Cronbach's Alpha } \\
\text { values }\end{array}$ \\
\hline \multicolumn{6}{|c|}{ City attractiveness (RM) } \\
\hline CRM1 & 3.87 & 1.311 & 17.99 & 0.86 & 0.871 \\
\hline CRM4 & 4.34 & 1.229 & 20.44 & 0.93 & 0.871 \\
\hline CRM6 & 4.89 & 0.457 & 7.41 & 0.43 & 0.886 \\
\hline CRM8 & 4.21 & 1.398 & 22.29 & 0.97 & 0.868 \\
\hline CRM9 & 3.86 & 1.482 & 17.59 & 0.85 & 0.871 \\
\hline CRM10 & 4.43 & 3.174 & 4.71 & 0.28 & 0.921 \\
\hline \multicolumn{6}{|c|}{ Positive psychological capital (PPC) } \\
\hline PS1 & 3.87 & 1.311 & 14.10 & 0.73 & 0.876 \\
\hline PS2 & 4.34 & 1.229 & 21.89 & 0.96 & 0.869 \\
\hline PS3 & 4.89 & 0.457 & 22.80 & 0.98 & 0.868 \\
\hline PS4 & 4.21 & 1.398 & 22.47 & 0.98 & 0.868 \\
\hline \multicolumn{6}{|c|}{ Bonding social capital (BSC) } \\
\hline B1 & 3.93 & 0.977 & 19.99 & 0.96 & 0.879 \\
\hline B2 & 4.29 & 0.806 & 15.12 & 0.79 & 0.884 \\
\hline B4 & 3.43 & 0.818 & 10.67 & 0.60 & 0.882 \\
\hline B6 & 3.93 & 0.935 & 8.73 & 0.51 & 0.889 \\
\hline \multicolumn{6}{|c|}{ Bridging social capital (BRSC) } \\
\hline BR1 & 1.75 & 1.003 & 1.63 & 0.10 & 0.890 \\
\hline BR2 & 4.28 & 0.820 & 16.78 & 0.90 & 0.888 \\
\hline BR4 & 4.38 & 0.821 & 18.48 & 0.97 & 0.886 \\
\hline BR6 & 4.27 & 0.938 & 4.65 & 0.28 & 0.884 \\
\hline
\end{tabular}

Chi-Square $=404.92 \quad \mathrm{df}=113 \quad$ P-value $=0.00000 \quad$ RMSEA $=0.096$

Source: Original calculations

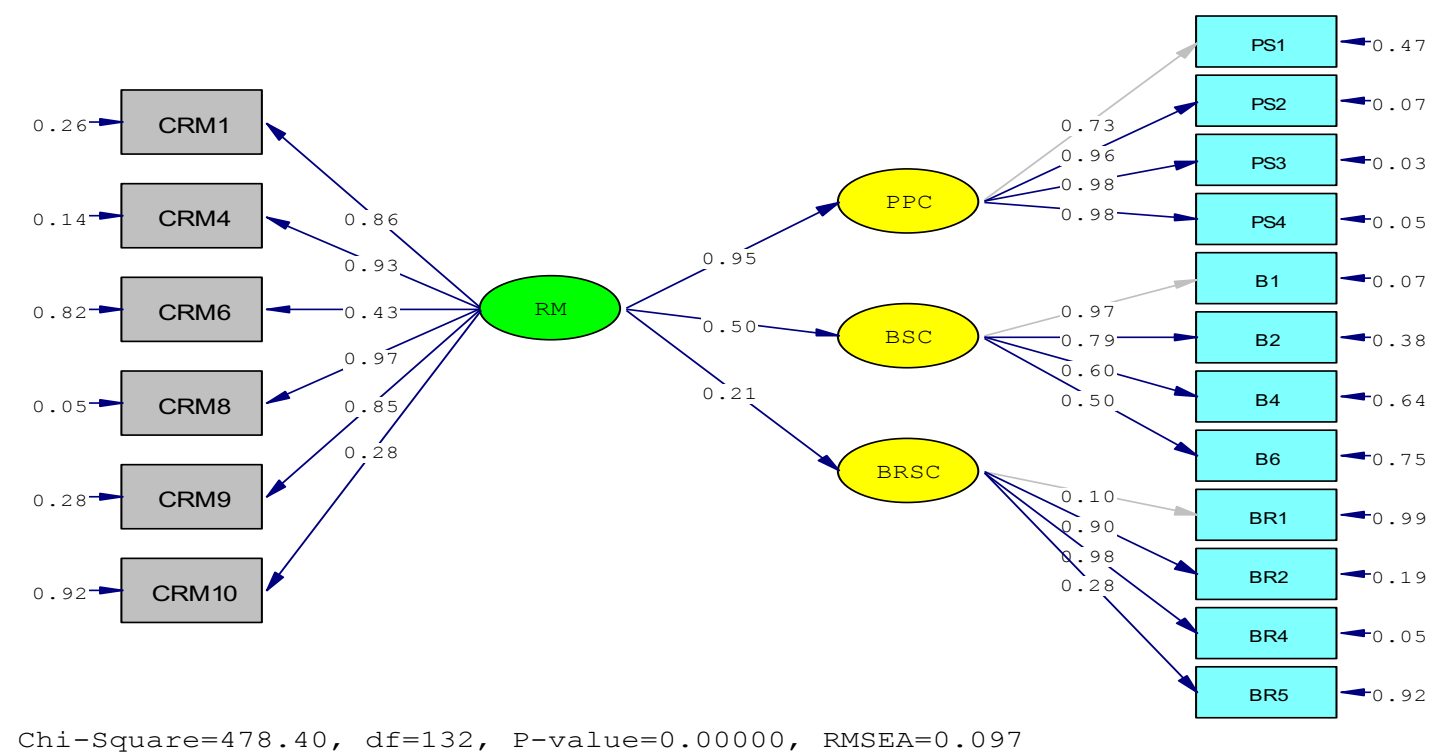

Figure 2. Urban attractiveness structural equation model and regression value

The results of the Structural Equation Modeling showed that all observed variables of the external latent variable "Attractiveness of the City - RM" have high values and are statistically significant. The most important observed variables are "CRM4- Health services and social facilities are better in the city" and "CRM8- I want to benefit from the city's education, infrastructure and transportation services".

Positive Psychological Capital (PPC) latent variable $(=0.95 ; \mathrm{t}=13.61)$ has a very strong positive effect on the Attractiveness of the City. The most important observed variables of the Positive Psychological Capital (PPC) latent variable are; "PS3- I will be pleased with my life in the city" and "PS4- My life in the city will change positively over time". 
The Bonding Social Capital (BSC) latent variable $(=0.50 ; \mathrm{t}=8.55)$ has a strong positive effect on the Attractiveness of the City. The most important observed variables of the binding social capital latent variable are; "B1I have a strong bond with my relatives in the city." and "B2- I care about my relatives in the city." was found as.

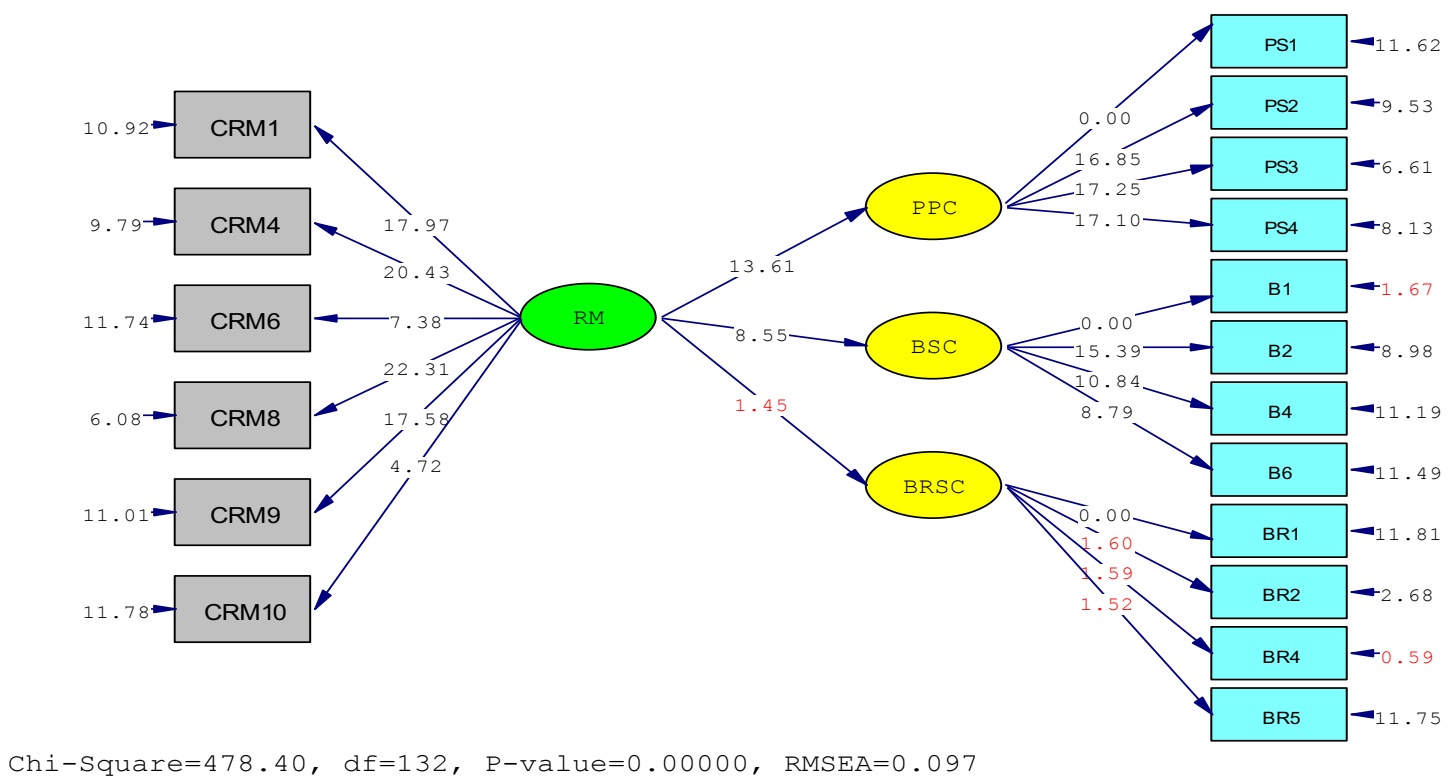

Figure 3. Urban attractiveness structural equation model $t$ values

The Bridging Social Capital (BRSC) latent variable (pozitif $=0.21 ; \mathrm{t}=1.45$ ) has a positive low-level effect on the Attractiveness of the City. However, as the $t$ value (1.45) \pm 1.96 was small, it was not found statistically significant at the 5\% significance level. The most important observed variables of the BRSC latent variable are; "BR2- I can communicate with any person." and BR4- Gives confidence the justice system to me. " has been.

Whether the data set confirms the theoretical structure to be tested or not is determined by using fit indices (Bentler \& Yuan, 1999). The criteria showing the compatibility of the model and data set are given in Table 3 below. The fact that the values in the fit indexes are close to 1 indicates that the fit between the data set and the model is very good, and zero represents the mismatch. In this study, fit index values are close to 1 . This situation shows that the working model and the data set are compatible.

Table 3. Fit Indices

\begin{tabular}{ccc}
\hline Fit indexes & Model Value & Fit Criterion \\
\hline$\chi 2 / d f$ & 3.62 & $0 \leq \chi 2 / \mathrm{sd} \leq 5$ \\
RMSEA & 0.096 & $0.00 \leq \mathrm{RMSEA} \leq 0.10$ \\
GFI & 0.90 & $0.90 \leq \mathrm{GFI} \leq 1$ \\
AGFI & 0.87 & $0.85 \leq \mathrm{AGFI} \leq 1$ \\
NFI & 0.95 & $0.90 \leq \mathrm{NFI} \leq 1.00$ \\
NNFI & 0.96 & $0.90 \leq \mathrm{NNFI}(\mathrm{TLI}) \leq 1.00$ \\
RFI & 0.94 & $0.90 \leq \mathrm{RFI} \leq 1.00$ \\
CFI & 0.96 & $0.90 \leq \mathrm{CFI} \leq 1.00$ \\
IFI & 0.96 & $0.90 \leq \mathrm{IFI} \leq 1.00$ \\
\hline
\end{tabular}

Source: Original calculations

\section{Conclusion and recommendations}

The 'attractiveness of the city' is based on the perception of a better life, higher welfare, and this hope drives rural migration. The fact that the resources and production opportunities available in the country are not equal among the regions cause differences in development between the regions. The settlements where industry and service sectors are concentrated and developed attract migrants from rural areas to cities by creating wage differences and new job opportunities. 
The study findings revealed empirical findings that the city is "attractive" due to the work, food, education, health, culture and comfort it contains. The positive psychological and social capital of the individuals affect the attractiveness of the city positively and to a high degree. Positive Psychological Capital (PPC) of individuals had a very strong positive effect on the attractiveness of the city $(=0.95 ; \mathrm{t}=13.61)$. The perception that life satisfaction will be higher in the city attracts individuals to cities. Again, the Bonding Social Capital (BSC) of individuals is one of the positive and important factors in the migration of individuals to cities $(=0.50 ; \mathrm{t}=8.55)$. Strong kinship ties in city centers, individuals' care about their relatives and always being in contact lead to information about the blessings of the city and encourages them to migrate to the city. Bridging Social Capital (BRSC) has a low (= $0.21 ; \mathrm{t}=1.45$ ) effect on the attractiveness of the city. Individuals who migrate from rural areas to urban centers cannot socialize much and find movement outside the community boundaries.

Rural migrations may come to an end if infrastructure and superstructure services in rural areas are quickly revised and parallel to urban areas. The creation of new jobs and income opportunities in rural areas, improvement and development moves in the fields of health, education, culture, sports, transportation and communication can also trigger a reverse migration. Basic inference that can be reached from the study; The main purpose that drives individuals to the attractiveness of the city is the desire for a more comfortable, more beautiful and high standard life.

In order to prevent rural migration, it is necessary to increase the welfare level of individuals living in rural areas, to increase their employment opportunities and to expand the services provided in urban centers in rural areas. For this;

- For the success of sustainable rural development programs and the prevention of migration, it is necessary to increase the opportunities and level of education and to ensure wide participation with an educational mobilization. For this purpose, village primary schools should be reopened and rural students at all levels should be provided with the opportunity to continue their education without being separated from their villages.

- Awareness of profitable agricultural production should be created with agricultural education.

- Agricultural support and subsidies should be expanded and living standards in rural areas should be raised.

- In rural settlements, infrastructure and superstructure should be equalized with urban areas.

- Health, education, cultural activities and sports opportunities offered by the city should also be available in the countryside.

- New income and employment opportunities such as rural tourism should be mobilized.

- Farmer cooperatives should be established and the productions of the farmers should be brought directly to the consumers.

- Finally, rural development agencies and coordinators should move from city centers to rural areas and carry out their activities in rural villages and campuses.

This study was conducted in a narrow area and with a small number of volunteer participants. Therefore, it may not be appropriate to generalize the findings and results. Conducting regional or national research on rural migration will yield more explanatory results.

\section{Author contribution statements}

Ş.Keleş contributed fully to the design and implementation of the research, to the analysis of the results and to the writing of the manuscript.

\section{Disclosure statement}

No potential conflict of interest was reported by the author.

\section{Ethics committee approval}

Data of this research was gathered in 2018. No potential conflict of interest was reported by the authors. All responsibility belongs to the researcher. All parties were involved in the research of their own free will. 


\section{References}

Adler, P. S., \& Kwon, S. W. (2002). Social capital: Prospects for a new concept. Academy of management review, 27(1), 1740.

Avey, J. B., Luthans, F., \& Jensen, S. M. (2009). Psychological capital: A positive resource for combating employee stress and turnover. Human resource management, 48(5), 677-693.

Balc1oğlu, I. (2007). Migration in social and psychological terms. Bilge Publishing.

Başel, H. (2007). Causes of Population Movements and Internal Migration in Turkey. Journal of Social Politics Conferences (53), 515-542.

Bentler, P. M., \& Yuan, K. H. (1999). Structural equation modeling with small samples: Test statistics. Multivariate behavioral research, 34(2), 181-197.

Blanthorne, C., Jones-Farmer, L. A., \& Almer, E. D. (2006). Why You Should Consider SEM: A Guide to Getting Started. Advances in Accounting Behavioral Research, 9, 179-207.

Bourdieu, P. (1989). Social space and symbolic power. Sociological theory, 7(1), 14-25.

Bourdieu, P., \& Wacquant, L. J. (1992). An invitation to reflexive sociology. Chicago: University of Chicago press.

Burt, R. S. (1999). The social capital of opinion leaders. The Annals of the American Academy of Political and Social Science, $566(1), 37-54$

Caprara, G. V., \& Cervone, D. (2003). Conception of Personality for a Psychology of Human Strengths: Personality as an Agentic, Self Regulating System. L. a. Aspinwall, Psychology of Human Strenghts: Fundamental Questions and Future Directions for a Positive Psychology. Washington (s. 61-74). DC American Psychological Association.

Coleman, J. S. (1988). Social capital in the creation of human capital. American journal of sociology, 94, 95-120.

Çağlayan, S. (2006). Theories of Migration, the Relationship between Migration and Immigration. Muğla University Journal of Social Sciences Institute (ILKE), 17, 67-91.

Dücan, E. (2016). Regional Socio-Economic Analysis of the Causes of Internal Migration in Turkey. Journal of Economic and Social Studies, 12(12), 167-183.

Fornell, C. G. (1987). A Second Generation of Multivariate Analysis: Classification of Methods and Implications for Marketing Research. In M. J. Houston (Ed.), Review of Marketing (pp. 407-450). Chicago: American Marketing Association.

Fukuyama, F. (2002). Social capital and development: The coming agenda. SAIS review, 22(1), 23-37.

Gable, S., \& Haidt, J. (2009). What (and why) is positive psychology. Review of General Psychology, 9, 103-110.

Gökçe, B. (1996). Turkey's Social Structure and Social Institutions. Ankara: Savaş Yayınevi.

Gür, T. H., \& Emel, U. (2004). The causes of migration to the cities in Turkey. Hacettepe University Journal of Economics and Administrative Sciences, 22(1), 23-38.

Gürbüz, M., \& Karabulut, M. (2008). Analysis of the relationships between rural migrations and socio-economic characteristics. Turkish Geographical Journal, 50, 37-60.

Harrison, L. E., \& Huntington, S. P. (2000). Culture matters: How values shape human progress (p. xvii). New York: Basic books.

Hershberger, S. L. (2003). The growth of structural equation modeling: 1994-2001. Structural Equation Modeling, 10(1), 35 46.

Hoyle, R.H. (1995). The structural equation modeling approach. In R.H. Hoyle (Ed.), Structural equation modeling: Concepts, issues, and applications (pp. 1-15). Thousand Oaks, CA: Sage.

İlhan, M., \& Çetin, B. (2014). Comparison of results of structural equation model (feed) analyzes performed using LISREL and AMOS programs. Journal of Measurement and Evaluation in Education and Psychology, 5(2), 26-42.

Jöreskog, K. G., \& Sörbom, D. (1993). LISREL 8: Structural equation modeling with the SIMPLIS command language. Scientific Software International.

Kahn, J. H. (2006). Factor analysis in counseling psychology research, training, and practice: Principles, advances, and applications. The counseling psychologist, 34(5), 684-718.

Karpat, H. (2003). Social Transformation in Turkey. Ankara: İmge kitapevi.

Kartal, K. (1978). Urbanization and Human: Changes in Human Attitudes and Behaviors During the Urbanization Process. Ankara: TODAİE.

Keleş, R. (1996). Urbanization Policies. Ankara: İmge Yayınevi.

Keskin, A., \& Keleş, Ş. (2018). Formation of the social capital by its dimensions in rural areas of Erzurum province in Turkey. JAPS: Journal of Animal \& Plant Sciences, 28(6), 1854-1867.

Kıray, M. B. (2007). Urbanization Articles. İstanbul: Bağlam Yayıncılık.

Korczynski, M. (2000). The Political Economy Of Trust. Journal of Management Studies, 37(1), 1-21.

Lee, E. S. (1969). A Theory of Migration. J. J. (Ed) içinde, Migration (s. 283-297). Great Britain: Cambridge University Press.

Leech, N. L., Barrett, K. C., Morgan, G. A., Clay, J. N., \& Quick, D. (2005). SPSS for intermediate statistics: Use and interpretation. Mahwah, NJ: Lawrence Earlbaum Associates. Inc., Publishers.

Lewis, G. J. (1982). Human Migration A Geographical Perspective. New York: St. Martin's Press.

Linley, A. P., Joseph, S., Harrington, S., \& Wood, A. M. (2006). Positive psychology: Past, present, and (possible) future. The journal of positive psychology, 1(1), 3-19.

Lomax, R. G., \& Schumacker, R. E. (2004). A beginner's guide to structural equation modeling. psychology press.

Luthans, F., Avolio, B. J., Avey, J. B., \& Norman, S. M. (2007). Positive psychological capital: Measurement and relationship with performance and satisfaction. Personnel psychology, 60(3), 541-572. 
Luthans, F., Vogelgesang, G. R., \& Lester, P. B. (2006). Developing the Psychological Capital of Resiliency. Human Resource Development Review, 5(1), 25-44.

Narayan, D., \& Pritchett, L. (1999). Cents And Sociability: Household Income And Social Capital In Rural Tanzania. Economic Development And Cultural Change, 47(4), 871-897.

Nitzl, C. (2016). The use of partial least squares structural equation modelling (PLS-SEM) in management accounting research: Directions for future theory development. Journal of Accounting Literature, 37, 19-35.

Özen, S., \& Aslan, S. (2006). Social Capital Potential of Turkish Society in Terms of Internal and External Social Capital Approaches: The Case of the Middle East Industry and Trade Center (OSTIM). Mediterranean FEAS Journal, 6(12), 130160

Palloni, A., Massey, D. S., Ceballos, M., Espinosa, K., \& Spittel, M. (2001). Social capital and international migration: A test using information on family networks. American Journal of Sociology, 106(5), 1262-1298.

Pituch, K. A., \& Stevens, J. P. (2009). Applied multivariate statistics for the social sciences (Vol. 21). New York and London: Routledge.

Raykov, T., \& Marcoulides, G. A. (2006). On multilevel model reliability estimation from the perspective of structural equation modeling. Structural Equation Modeling, 13(1), 130-141.

Sağlam, S. (2006). Turkey's internal migration and urbanization. Turkish Studies, 5, 33-44.

Sargut, A. S. (2003). The role of trust in the formation of organizational structures and economic transactions in institutional areas. Ankara: Vadi Yayınları.

Sencer, Y. (1979). Urbanization in Turkey. Ankara: Ministry of Culture Publications.

Spilimbergo, A., \& Ubeda, L. (2004). Family attachment and the decision to move by race. Journal of Urban Economics, 55(3), 478-497.

Stouffer, S. A. (1940). Intervening Opportunities: A Theory Relating Mobility and Distance. American Sociological Review, $5(6), 845-867$

Tabachnick, B. G., Fidell, L. S., \& Ullman, J. B. (2007). Using multivariate statistics (Vol. 5). Boston, MA: Pearson.

Weston, R., \& Gore Jr, P. A. (2006). A brief guide to structural equation modeling. The counseling psychologist, 34(5), 719751.

Woolcock, M. (2002). Social capital in theory and practice: where do we stand. Social capital and economic development: Well-being in developing countries, 1(2), 18-39.

Yamane, T. (1967). Statistics: an introductory analysis, 2nd edn, Harper and Row, New York. 